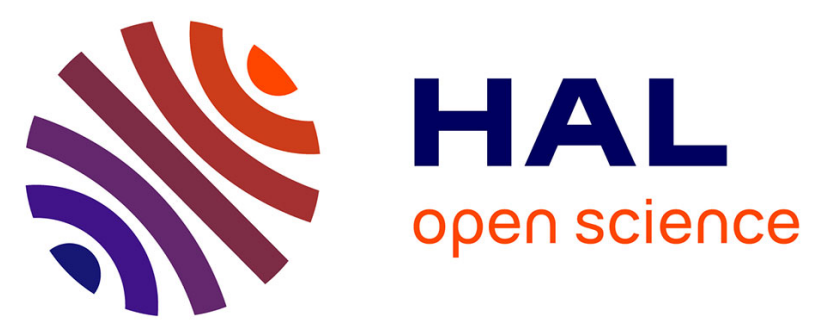

\title{
Effect of early hyperoxemia on the outcome in servere blunt chest trauma: A propensity score-based analysis of a single-center retrospective cohort
}

Gary Duclos, Adrien Rivory, Noémie Rességuier, Emmanuelle Hammad, Coralie Vigne, Zoé Meresse, Bruno Pastène, Xavier-Benoit d'Journo, Samir Jaber, Laurent Zieleskiewicz, et al.

\section{To cite this version:}

Gary Duclos, Adrien Rivory, Noémie Rességuier, Emmanuelle Hammad, Coralie Vigne, et al.. Effect of early hyperoxemia on the outcome in servere blunt chest trauma: A propensity score-based analysis of a single-center retrospective cohort. Journal of Critical Care, 2021, 63, pp.179-186. 10.1016/j.jcrc.2020.09.008 . hal-02941991

\author{
HAL Id: hal-02941991 \\ https://hal.science/hal-02941991
}

Submitted on 14 Oct 2020

HAL is a multi-disciplinary open access archive for the deposit and dissemination of scientific research documents, whether they are published or not. The documents may come from teaching and research institutions in France or abroad, or from public or private research centers.
L'archive ouverte pluridisciplinaire HAL, est destinée au dépôt et à la diffusion de documents scientifiques de niveau recherche, publiés ou non, émanant des établissements d'enseignement et de recherche français ou étrangers, des laboratoires publics ou privés. 


\title{
Effect of early hyperoxemia on the outcome in servere blunt chest trauma: A propensity score-based analysis of a single-center retrospective cohort
}

\author{
Gary Duclos ${ }^{\mathrm{a}, *}$, Adrien Rivory ${ }^{\mathrm{a}}$, Noémie Rességuier ${ }^{\mathrm{b}, \mathrm{c}}$, Emmanuelle Hammad ${ }^{\mathrm{a}}$, Coralie Vigne ${ }^{\mathrm{a}}$, Zoé Meresse ${ }^{\mathrm{a}}$, \\ Bruno Pastène ${ }^{a}$, Xavier-Benoit D'journo ${ }^{d}$, Samir Jaber ${ }^{e}$, Laurent Zieleskiewicz ${ }^{\text {a,f }}$, Marc Leone ${ }^{a}$ \\ a Aix Marseille University, Assistance Publique Hôpitaux de Marseille, Nord Hospital, Department of Anesthesiology and Critical Care, Marseille, France

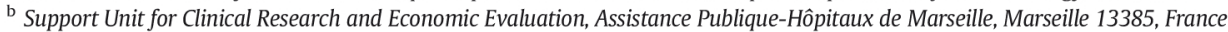 \\ c Aix-Marseille University, EA 3279 CEReSS - Health Service Research and Quality of Life Center, Marseille, France. \\ d Aix-Marseille University, Assistance Publique Hôpitaux de Marseille, Nord Hospital, Department of Thoracic Surgery, Marseille, France \\ e Medical-Surgical Intensive Care Unit, University Hospital of Montpellier and INSERM U1046, Montpellier, France \\ f Center for Cardiovascular and Nutrition Research (C2VN), Aix Marseille Université, INSERM, INRA, Marseille, France
}

Keywords:

Blunt chest trauma

Hyperoxia

ARDS

Pneumonia

Critical care

Mechanical ventilation

\begin{abstract}
A B S T R A C T
Purpose: Our study aimed to explore the association between early hyperoxemia of the first $24 \mathrm{~h}$ on outcomes in patients with severe blunt chest trauma.

Materials and methods: In a level I trauma center, we conducted a retrospective study of 426 consecutive patients. Hyperoxemic groups were classified in severe (average $\mathrm{PaO}_{2} \geq 200 \mathrm{mmHg}$ ), moderate $(\geq 150 \mathrm{and}<200 \mathrm{mmHg}$ ) or mild ( $\geq 100$ and $<200 \mathrm{mmHg}$ ) and compared to control group ( $\geq 60$ and $<100 \mathrm{mmHg}$ ) using a propensity score based analysis. The first endpoint was the incidence of a composite outcome including death and hospital-acquired pneumonia occurring from admission to day 28 . The secondary endpoints were the incidence of death, the number of hospital-acquired pneumonia, mechanical ventilation-free days and intensive care unitfree day at day 28.

Results: The incidence of the composite endpoint was lower in the severe hyperoxemia group $(\mathrm{OR}, 0.25 ; 95 \% \mathrm{CI}$, $0.09-0.73 ; P<0.001)$ compared with control. The 28-day mortality incidence was lower in severe (OR, 0.23; $95 \% \mathrm{CI}, 0.08-0.68 ; P<0.001$ ) hyperoxemia group (OR, 0.41;95\%CI, 0.17-0.97; $P=0.04$ ). Significant association was found between hyperoxemia and secondary outcomes.

Conclusion: In our cohort early hyperoxemia during the first $24 \mathrm{~h}$ of admission after severe blunt chest trauma was not associated with worse outcome.
\end{abstract}

\section{Background}

Trauma is the leading cause of mortality and morbidity in active population, representing a significant burden for the community $[1,2]$. Blunt chest trauma is found in nearly $50 \%$ of trauma [2]. It has an attributable mortality rate of around 30\% [2]. Lung injury may lead to organ failure by hypoxia and aggravate associated injuries through impaired blood gas exchange [3-5].

Patients with blunt chest trauma require oxygen administration and mechanical ventilation to prevent hypoxia [6]. However, In trauma patients, guidelines do not advise how oxygen should be administered, the main goal being to prevent hypoxemia [6-8]. Eskesen et al. found

\footnotetext{
* Corresponding author.

E-mail address: garyduclos@ap-hm.fr (G. Duclos).
}

that half of trauma patients administered with prehospital oxygen were hyperoxemic. [9] In a prospective study, McMullan et al. reported that prehospital oxygen was administered to $63 \%$ of trauma patients, while no indication was found in $25 \%$ of cases [10]. Liberal use of oxygen can result in hyperoxemia, the effects of which remain uncertain in view of the clinical research in the field and depending on the patient population [11-14].

To the best of our knowledge, no study has been conducted to assess the effect of hyperoxemia in the early phase of the management of patients with severe blunt chest trauma [8]. Our retrospective study aimed to assess the effect of early hyperoxemia on a composite endpoint in patients with severe blunt chest trauma. We hypothesized that hyperoxemia would be associated with higher mortality and morbidity, longer duration of mechanical ventilation and intensive care unit (ICU) stay. 


\section{Methods}

We conducted a retrospective, observational, single-center study in a level I trauma center university hospital (Nord Hospital, Marseille, France). We adhered to the Strengthening the Reporting of Observational Studies in Epidemiology statement for observational studies [15]. All trauma patients admitted with severe blunt chest trauma were eligible. Severe blunt chest trauma was defined as a chest Abbreviated Injury Scale (AIS) $>2$ and an Injury Severity Score (ISS $>15$ ) [16]. The exclusion criteria were $\mathrm{PaO}_{2}: \mathrm{FiO}_{2}$ ratio $<200 \mathrm{mmHg}$ at admission, delay between trauma and admission $>24 \mathrm{~h}$, ICU length of stay $<24 \mathrm{~h}$, penetrating trauma, patients without blood gas sampling or a whole-body computed tomography (CT) scan during the first $24 \mathrm{~h}$ after admission, pregnancy, and patients $<18$ years of age.

This study received the approval of our national ethics committee (Comité d'Ethique de la Recherche en Anesthésie-Réanimation) number SFAR - CERAR 00010254-2018-122. The ethics committee waived the need for written consent, according to the French law on retrospective studies [17].

\subsection{Data collection}

All data were extracted from the patient electronic file. The partial arterial oxygen pressures $\left(\mathrm{PaO}_{2}\right)$ were extracted from the blood gases collected during the first $24 \mathrm{~h}$ after admission. The average values of $\mathrm{PaO}_{2}$ defined either the severe hyperoxemia group (average $24 \mathrm{~h}$ $\mathrm{PaO}_{2} \geq 200 \mathrm{mmHg}$ ), the moderate hyperoxemia group (average $24 \mathrm{~h}$ $\mathrm{PaO}_{2} \geq 150$ and $<200 \mathrm{mmHg}$ ), the mild hyperoxemia group (average $24 \mathrm{~h} \mathrm{PaO}_{2} \geq 100$ and $<150 \mathrm{mmHg}$ ) or the control group (average $24 \mathrm{~h} \mathrm{PaO}_{2}<100 \mathrm{mmHg}$ ).

At ICU admission the data collected were sex, age, co-morbidities, presence of severe traumatic brain injury (TBI), ISS, Sequential Organ Failure Assessment Score, Simplified Acute Physiology Score II, Glasgow Coma Scale score, hemodynamic shock, use of invasive mechanical ventilation (i.e., intubated patients) or spontaneous breathing (i.e., nonintubated patients), inspired oxygen fraction $\left(\mathrm{FiO}_{2}\right)$, and oxygen flow through a nasal cannula or facial mask in the spontaneously breathing patients. Chest trauma were detailed as hemothorax, pneumothorax, number and side of rib fracture(s), flail chest, or pulmonary contusion.

In cases of non-intubated patients using a standard nasal cannula or facial mask, inspired oxygen fraction $\left(\mathrm{FiO}_{2}\right)$ was estimated using the following formula from a previous study: [18].

$\mathrm{FiO}_{2}=21+($ oxygen flow in $\mathrm{L} / \min \times 3) \%$

In cases of high flow nasal cannula ( $40 \mathrm{~L} / \mathrm{min}$ or more) $\mathrm{FiO}_{2}$ was directly reported.

The patients with TBI were considered as severe in the presence of an injury shown on a CT scan and if they had a Glasgow Coma Scale score $<9$. Shock was defined as a serum lactate concentration above $2 \mathrm{mmol} / \mathrm{L}$ and the need for vasopressors to maintain a mean arterial pressure $>65 \mathrm{mmHg}$. The patients with severe TBI receiving norepinephrine infusion to maintain their cerebral perfusion pressure above $60 \mathrm{mmHg}$ were not considered in shock if the serum lactate concentration was below $2 \mathrm{mmol} / \mathrm{L}$.

At day 28, we collected data on the incidence of death, hospitalacquired pneumonia (HAP), and acute respiratory distress syndrome (ARDS). ARDS was defined according to the Berlin criterion $48 \mathrm{~h}$ after admission [19]. HAP was defined as suspected sepsis associated with lung opacity diagnosed with a chest X-ray or a CT scan and requiring antimicrobial treatment $[20,21]$. The number of HAP-free, mechanical ventilation-free, and ICU-free days was calculated from day 28 . If death occurred before day 28 , the count was assigned to zero.

\subsection{Outcomes}

The main outcome was the incidence of a composite endpoint defined as the incidence of HAP and/or death between ICU admission and day 28 . The secondary outcomes were the incidence of death, the number of HAP-free, mechanical ventilation-free and ICU-free days, and ARDS incidence at day 28.

\subsection{Data analysis}

The demographic, clinical, and biological features were described and compared between the four groups (three hyperoxemia groups and a control group). The quantitative values were described as means ( \pm standard derivation [SD]) or medians (25th and 75th interquartile $[\mathrm{IQR}])$ and compared using the analysis of variance when appropriate and otherwise the Kruskal-Wallis test. The qualitative values were described as numbers (percentages) and compared using the Chi-square test when appropriate and otherwise the Fisher test.

To assess the differences between the severe; the moderate; the mild hyperoxemia and the control groups, the average $\mathrm{PaO}_{2}$ during the first $24 \mathrm{~h}$, taken from the values of the first, last, and all the intermediate blood gases, were compared.

Univariate analyses were performed to identify the factors associated with the main and the secondary outcomes.

Logistic and linear regression models were built to assess the impact of hyperoxemia on main and secondary outcomes. To reduce the bias by indication, propensity score-weighted analyses were performed. [22] The propensity score model included baseline data (age, sex, use of prehospital mechanical ventilation, shock at admission, chest AIS $>3$ and ISS [sum of the most severe injuries, excluding the thorax]). Boosted logistic regression was used to calculate the propensity score as the exposure variable contained 4 levels. [23] Weights were calculated for the average treatment effect. Regression models applied on weighted data were adjusted for $\mathrm{FiO}_{2}$ level at admission. As a sensitivity analysis of the composite endpoint, multivariate regression models were built taking into account the average value of $\mathrm{PaO}_{2}$ over the first $24 \mathrm{~h}$ without categorization. Furthermore, we estimated the causal effect of $\mathrm{PaO}_{2}$ time-varying exposure on the composite endpoint, using approach based on inverse probability weighting (IPW) of marginal structural model (MSM) to adjust for confounding (age, sex, use of prehospital mechanical ventilation, shock at admission, chest AIS $>3$ and ISS).

All analyses were performed using R software, and the twang package was used for propensity score-bases analyses (mnps function was used to calculate propensity score). [24] ipw R Package was used to perform the MSM analysis.

\section{Results}

From July 2013 to December 2017, 1018 trauma patients were admitted to the ICU. A total of 424 patients met the inclusion criteria (Flowchart Fig. 1). One hundred eighty two patients were excluded because of length of stay of less than $24 \mathrm{~h}$. From those, 174 died during this period and eight were transferred to another ICU because of the need of extra corporeal circulation. The baseline features are provided in Table 1 . Three hundred and thirty-two (78\%) patients were males, with a median age of 36 (24-54) years and a median ISS of 29 (25-41). At ICU admission, 184 (43\%) patients were mechanically ventilated. Shock criteria and severe TBI were found in 147 (35\%) and 81 (19\%) patients, respectively. Sixty-six (16\%) patients had an average $24 \mathrm{~h} \mathrm{PaO}_{2} \geq 200 \mathrm{mmHg}, 128$ (30\%) patients had an average $24 \mathrm{~h}$ $\mathrm{PaO} 2 \geq 150$ and $<200 \mathrm{mmHg}$ and $172(41 \%)$ patients had an average $24 \mathrm{~h} \mathrm{PaO2} \geq 100$ and $<150 \mathrm{mmHg}$. The control group was composed with 58 (13\%) patients who had an average $24 \mathrm{~h} \mathrm{PaO}_{2} \geq 60$ and $<100 \mathrm{mmHg}$. The average $24 \mathrm{~h} \mathrm{PaO}_{2}$ was $242( \pm 50) \mathrm{mmHg}$ in the severe hyperoxemia group, $173( \pm 15) \mathrm{mmHg}$ in the moderate hyperoxemia group, $125( \pm 15) \mathrm{mmHg}$ in the mild hyperoxemia 


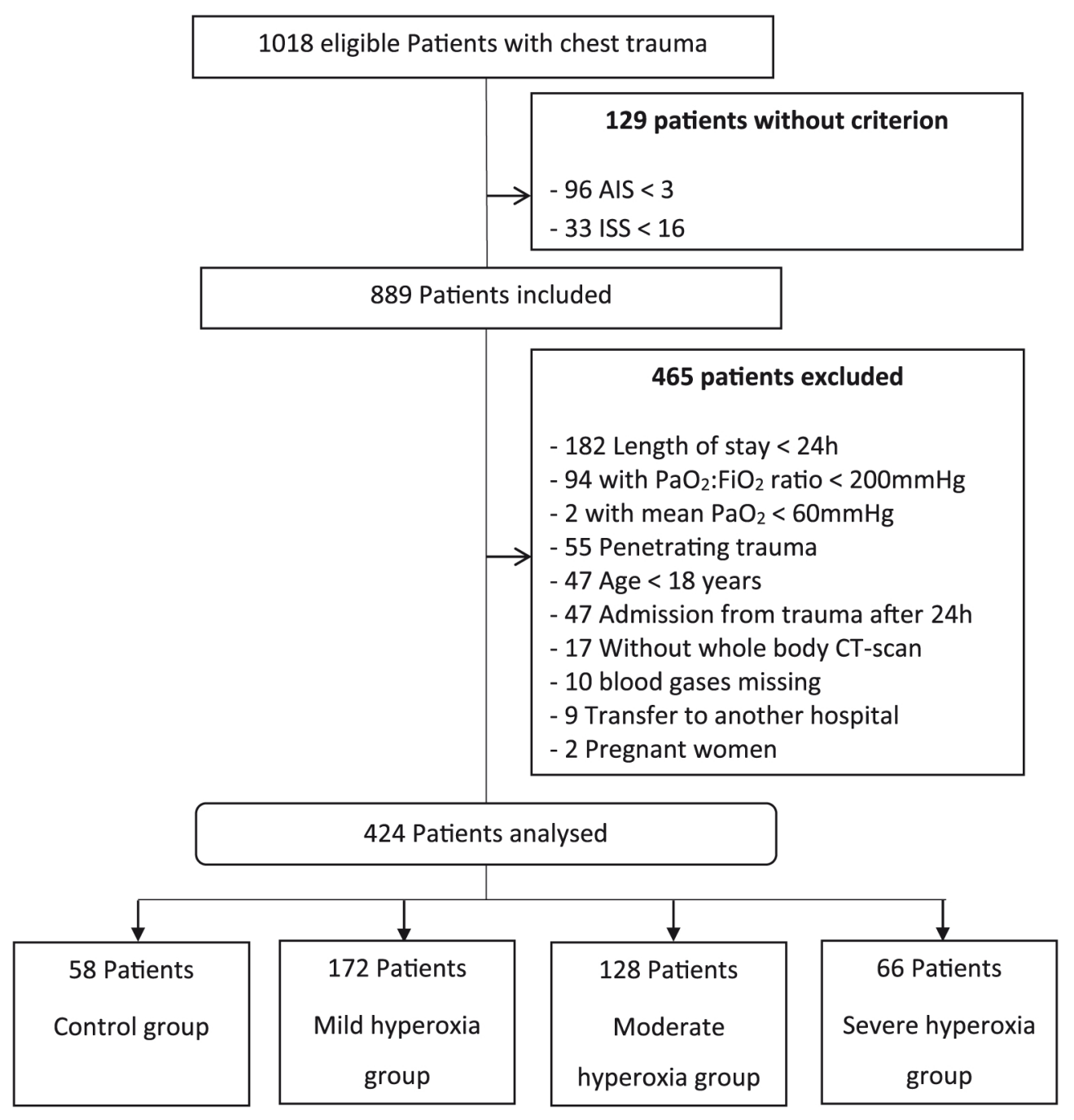

Fig. 1. Flowdiagram AIS: Abbreviated Injury Scale; ISS: Injury Scale Score.

group and $87( \pm 9) \mathrm{mmHg}$ in the control group $(P<0.001)$. The mean $\mathrm{PaO}_{2}$ values over time of the first, intermediate, and last blood gases in the first $24 \mathrm{~h}$ after admission were significantly higher $(P<0.001)$ in the severe and moderate hyperoxemia group than in the control group (Fig. 2).

Severity was higher in the severe and moderate hyperoxemia group compared with control group based on higher SAPS II score $(P<0.01)$, ISS $(P<0.01)$, SOFA score $(P<0.01)$ at admission (Table 1$)$. Severe hyperoxemia group patients also received significantly more blood transfusion $(P<0.01)$, more fresh frozen plasma, $(P<0.01)$, more mechanical ventilation $(P<0.001)$. They also presented more shock at admission $(P=0.02)$ and severe TBI $(P=0.04)$ than the control group (Table 1$)$. No significant difference was found regarding severity of thoracic AIS between groups $(P=0.1)$ (Table 1$)$.

\subsection{Outcomes}

A total of 77 (18\%) patients met the criteria for the first endpoint. Results of propensity score analysis are summarized in Fig. 3. A significant association was found between early hyperoxemia and the incidence of the composite endpoint in the severe hyperoxemia group(adjusted odds ratio $[\mathrm{OR}], 0.11$; 95\% confidence interval [CI], 0.02-0.59; $P=0.01)$. No significant difference was found in the moderate hyperoxemia and the mild hyperoxemia group (adjusted OR, 0.32;
95\% CI, 0.08-1.31; $P=0.1$ and adjusted OR, 0.55; 95\% CI, 0.16-1.81; $P=0.3$ respectively). Regarding the secondary endpoints: 28 -day mortality rate was lower in both severe (adjusted OR, 0.06; 95\% CI, $0.01-0.52 ; P=0.01$ ) and in the moderate hyperoxemia group (adjusted OR, $0.15 ; 95 \% \mathrm{Cl}, 0.02-1.00 ; P=0.05$ ) but none in the mild hyperoxemia group adjusted $\mathrm{OR}, 0.36 ; 95 \% \mathrm{CI}, 0.07-1.87 ; P=0.2$ ). No significant difference was found between groups regarding ARDS occurrence (adjusted OR, 0.10; 95\%CI, 0.01-2.51; $P=0.2$, adjusted OR, $0.22 ; 95 \% \mathrm{CI}$; $0.04-1.27 ; P=0.1$ and adjusted $\mathrm{OR}, 0.3 ; 95 \% \mathrm{CI}, 0.07-1.46 ; P=0.1$ respectively). Early hyperoxemia exposure was associated with an increased number of HAP-free days in the severe hyperoxemia group (adjusted beta coefficient, 11 days; $95 \% \mathrm{CI}, 6-16 ; P=0.001$ ), in the moderate hyperoxemia group (adjusted beta coefficient, 6 days; 95\% CI, $1-10 ; P=0.01$ ) but not in the mild hyperoxemia group (adjusted beta coefficient, 3 days; $95 \% \mathrm{CI},-1-8 ; P=0.1$ ).

Early hyperoxemia was significantly associated with improved outcome regarding Mechanical ventilation-free days and ICU-free days in the severe hyperoxemia and in the moderate hyperoxemia group but not in the mild hyperoxemia group (Fig. 3).

\subsection{Sensitivity analysis}

Results from multivariate regression model from mean $24 \mathrm{~h} \mathrm{PaO}_{2}$ and from marginal structural model from each available values of 


\begin{tabular}{|c|c|c|c|c|c|c|}
\hline & $\begin{array}{l}\text { All patients } \\
(n=424)\end{array}$ & $\begin{array}{l}\text { Control group } \\
(n=58)\end{array}$ & $\begin{array}{l}\text { Mild hyperoxia group } \\
(n=172)\end{array}$ & $\begin{array}{l}\text { Moderate hyperoxia group } \\
(n=128)\end{array}$ & $\begin{array}{l}\text { Severe hyperoxia group } \\
(n=66)\end{array}$ & $P$ \\
\hline \multicolumn{7}{|l|}{ Patient characteristics } \\
\hline Sex male (\%) & $330(78)$ & $51(88)$ & $135(78)$ & $101(79)$ & $43(65)$ & 0.02 \\
\hline Age (years) a & $36(25-54)$ & $50(33-64)$ & $36(25-55)$ & $35(24-49)$ & $31(23-45)$ & $<0.01$ \\
\hline SAPS II ${ }^{a}$ & $33(22-45)$ & $27(20-38)$ & $30(21-46)$ & $37(25-50)$ & $38(25-50)$ & $<0.01$ \\
\hline SOFA ${ }^{a}$ & $3(1-6)$ & $2(1-4)$ & $3(1-6)$ & $4(2-7)$ & $5(2-7)$ & $<0.01$ \\
\hline ISS $^{a}$ & $29(25-41)$ & $29(21-34)$ & $29(22-41)$ & $33(27-41)$ & $34(26-41)$ & $<0.01$ \\
\hline \multicolumn{7}{|l|}{ Chronic co-morbidities (\%) } \\
\hline Chronic respiratory failure & $18(4)$ & $5(9)$ & $9(5)$ & $1(1)$ & $3(5)$ & 0.04 \\
\hline Chronic cardiac failure & $26(6)$ & $7(12)$ & $14(8)$ & $2(2)$ & $3(5)$ & 0.01 \\
\hline Arterial hypertension & $45(11)$ & $13(22)$ & $20(12)$ & $7(5)$ & $5(8)$ & $<0.01$ \\
\hline Diabetes & $13(3)$ & $0(0)$ & $12(7)$ & $1(1)$ & $0(0)$ & $<0.01$ \\
\hline Cancer & $6(1)$ & $0(0)$ & $3(2)$ & $3(2)$ & $0(0)$ & 0.63 \\
\hline Epilepsy & $5(1)$ & $0(0)$ & $2(1)$ & $3(2)$ & $0(0)$ & 0.58 \\
\hline Psychiatric disease & $31(7)$ & $6(11)$ & $11(6)$ & $8(6)$ & $6(9)$ & 0.62 \\
\hline Anticoagulant therapy & $32(8)$ & $9(16)$ & $16(9)$ & $4(3)$ & $3(5)$ & 0.02 \\
\hline \multicolumn{7}{|l|}{ Chest lesions } \\
\hline Chest AIS ${ }^{a}$ & $4(3-4)$ & $4(3-4)$ & $4(3-4)$ & $4(3-4)$ & $4(3-4)$ & 0.87 \\
\hline$A I S=3(\%)$ & $174(41)$ & $22(38)$ & $67(39)$ & $61(48)$ & $24(36)$ & 0.33 \\
\hline AIS $=4$ or $5(\%)$ & $250(59)$ & $36(62)$ & $105(61)$ & $67(52)$ & $42(64)$ & \\
\hline Hemo-pneumothorax (\%) & $279(66)$ & $41(71)$ & $121(70)$ & $86(67)$ & $31(47)$ & $<0.01$ \\
\hline Rib fracture (s) (\%) & $283(67)$ & $45(78)$ & $119(69)$ & $79(62)$ & $40(61)$ & 0.11 \\
\hline Bilateral RF (\%) & $96(23)$ & $19(33)$ & $35(20)$ & $32(25)$ & $10(15)$ & 0.09 \\
\hline$R F>2(\%)$ & $233(54)$ & $40(69)$ & $93(54)$ & $65(51)$ & $33(50)$ & 0.10 \\
\hline Pulmonary contusion (\%) & $293(69)$ & $34(51)$ & $113(66)$ & $93(73)$ & $53(80)$ & 0.04 \\
\hline \multicolumn{7}{|l|}{ Type of admission (\%) } \\
\hline Primary & $333(79)$ & $40(69)$ & $126(73)$ & $107(84)$ & $60(91)$ & $<0.01$ \\
\hline Secondary & $91(21)$ & $18(31)$ & $46(27)$ & $21(16)$ & $6(9)$ & \\
\hline \multicolumn{7}{|l|}{ Vital functions } \\
\hline Pre-admission MV (\%) & $184(43)$ & $11(19)$ & $57(33)$ & $72(56)$ & $44(67)$ & $<0.01$ \\
\hline Hemodynamic shock (\%) & $147(35)$ & $10(17)$ & $57(33)$ & $50(39)$ & $30(45)$ & 0.01 \\
\hline Pre-admission CRA (\%) & $14(3)$ & $2(3)$ & $5(3)$ & $5(4)$ & $2(3)$ & 0.98 \\
\hline TBI (\%) & $232(55)$ & $24(41)$ & $85(42)$ & $81(63)$ & $42(64)$ & $<0.01$ \\
\hline Severe TBI (\%) & $81(19)$ & $3(5)$ & $31(18)$ & $32(25)$ & $15(23)$ & 0.01 \\
\hline Glasgow Scale Score ${ }^{a}$ & $15(10-15)$ & $15(14-15)$ & $15(13-15)$ & $14(9-15)$ & $14(9-15)$ & $<0.01$ \\
\hline \multicolumn{7}{|l|}{ Respiratory variables } \\
\hline $\mathrm{FiO}_{2}{ }^{b}$ & $0.57( \pm 0.2)$ & $0.31( \pm 0.1)$ & $0.50( \pm 0.2)$ & $0.66( \pm 0.2)$ & $0.81( \pm 0.2)$ & $<0.01$ \\
\hline $\mathrm{PaO}_{2}: \mathrm{FiO}_{2}$ ratio $^{b}$ & $354( \pm 84)$ & $321( \pm 82)$ & $337( \pm 78)$ & $375( \pm 82)$ & $388( \pm 84)$ & $<0.01$ \\
\hline $\mathrm{PaO}_{2}$ AVG. $\mathrm{mmHg}^{b}$ & $152( \pm 53)$ & $87( \pm 9)$ & $125( \pm 15)$ & $173( \pm 15)$ & $243( \pm 50)$ & $<0.01$ \\
\hline $\mathrm{PaO}_{2} \mathrm{MAX} \cdot \mathrm{mmHg}^{b}$ & $215( \pm 93)$ & $99( \pm 21)$ & $176( \pm 50)$ & $259( \pm 68)$ & $332( \pm 77)$ & $<0.01$ \\
\hline \multicolumn{7}{|l|}{ Treatments } \\
\hline Surgery (\%) & $187(44)$ & $12(21)$ & $75(44)$ & $66(52)$ & $34(52)$ & $<0.01$ \\
\hline Embolization (\%) & $23(5)$ & $1(4)$ & $10(6)$ & $8(6)$ & $3(5)$ & 0.92 \\
\hline Red Blood Cells ${ }^{b}$ & $1( \pm 3)$ & $0.3( \pm 1)$ & $1( \pm 3)$ & $2( \pm 4)$ & $2( \pm 3)$ & $<0.01$ \\
\hline FFP $^{b}$ & $1( \pm 3)$ & $0.2( \pm 1)$ & $1( \pm 3)$ & $1( \pm 3)$ & $2( \pm 3)$ & 0.03 \\
\hline Platelets $^{b}$ & $0.1( \pm 0)$ & $0( \pm 0)$ & $0.2( \pm 0)$ & $0.2( \pm 1)$ & $0.1( \pm 0)$ & 0.06 \\
\hline
\end{tabular}

AIS : Abbreviated Injury Scale; CRA: Cardiorespiratory Arrest; FFP : Fresh Frozen Plasma; FiO2 : Fraction of inspired oxygen; ISS : Injury Severity score; MV: Mechanical Ventilation; PaO2 AVG: Mean Partial Pressure of arterial oxygen; PaO2 MAX: Maximal Partial Pressure of arterial oxygen; RBC: Red Blood Cells; RF: Rib fracture; SAPS II: Simplified Acute Physiology Score II; SD: Standard Deviation; SOFA D1 : Sepsis-related Organ Failure Assessment at Day 1; TBI: Traumatic Brain Injury

a Median (Interquartile range).

b $\operatorname{Mean}( \pm S D)$.

$\mathrm{PaO}_{2}$ other time are presented in Table 2. Complete analysis with cofounding factor are presented in supplemental Tables 1 and 2.

Regarding multivariate regression model, no significant association was found between mean $24 \mathrm{~h} \mathrm{PaO}_{2}$ and occurrence of the composite endpoint $(P=0.2)$, with occurrence of death $(P=0.1)$ and with number of HAP-free days $(P=0.1)$. However, lower number of mechanical ventilation free days and ICU-free days were significantly associated with mean $24 \mathrm{~h} \mathrm{PaO}_{2}(P=0.001$ and $P=0.003$ respectively). (Table 2 and supplemental table 1 ).

Considering adjusted marginal structural model analysis no significant association was found between values of $\mathrm{PaO}_{2}$ other time and occurrence of the composite endpoint $(P=0.4)$, with occurrence of death $(P=0.2)$. Lower number of HAP-free days $(P=0.003)$ of mechanical ventilation free days $(P=0.01)$ and ICU-free days were significantly associated with values of $\mathrm{PaO}_{2}(P=0.04)$. (Table 2 and supplemental Table 2).

\section{Discussion}

In this retrospective study, divergent with our hypothesis, hyperoxemia was not associated with more complications, including death and/or HAP and/or ARDS. Hyperoxemia may be also associated with increased numbers of HAP-free, mechanical ventilation-free, and ICU-free days.

In our study, early hyperoxemia may be associated with a decreased incidence of HAP. This finding suggests that early hyperoxemia may be associated with a protective effect in patients with severe blunt chest trauma. The first hypothesis can be related to the antimicrobial effect of limited hyperoxia exposure [22-24]. Perioperatively, hyperoxia exposure is a recommended strategy to reduce the rate of surgical site infection [25]. However, a meta-analysis comparing liberal and restrictive use of oxygen in critically ill patients was inconclusive regarding the effect of hyperoxia exposure on pneumonia (relative risk 1.00; 95\% CI, 


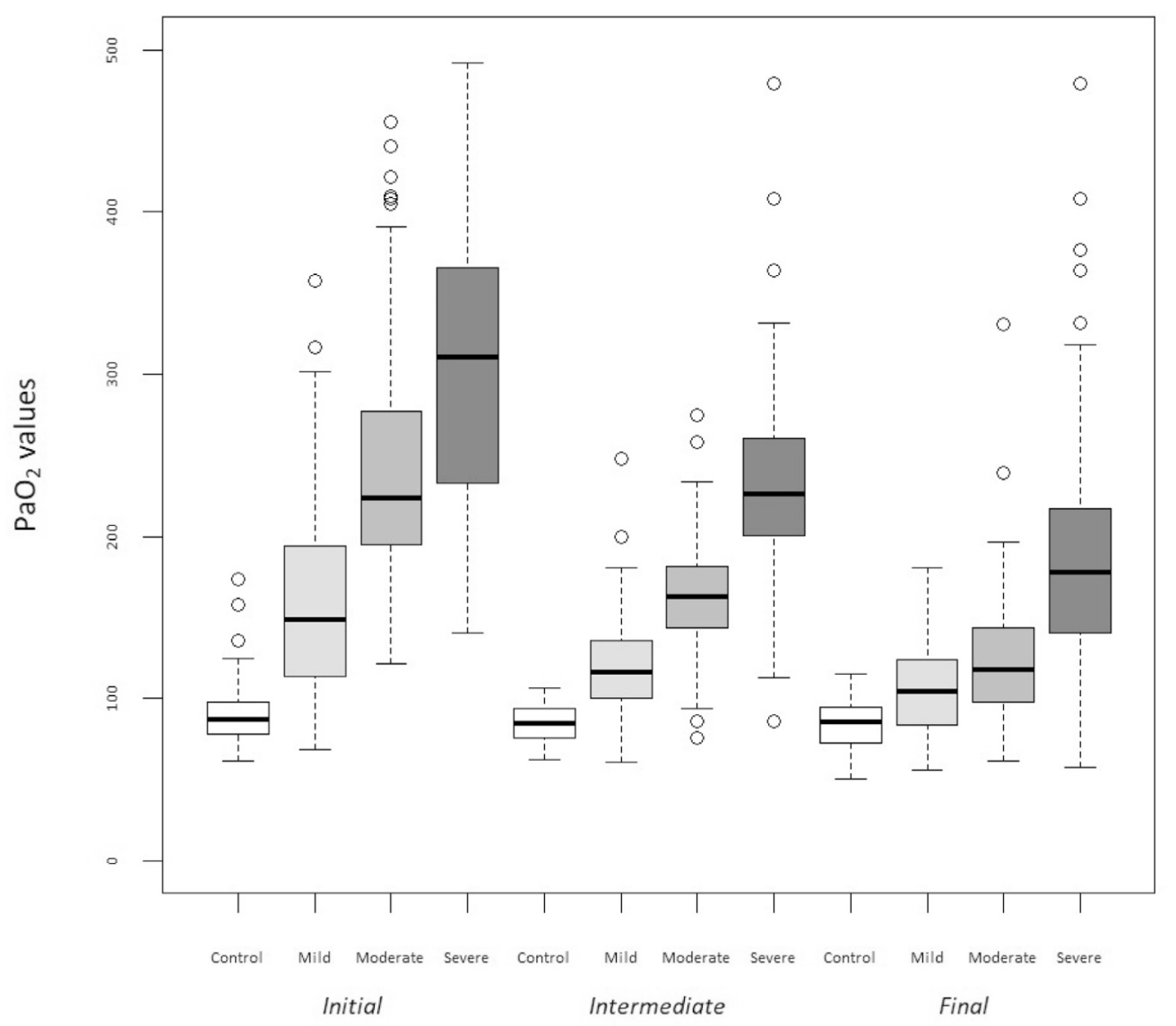

Fig. 2. Comparison of $\mathrm{PaO}_{2}$ of initial, last and all intermediate arterial blood gases between severe, moderate, mild hyperoxemia groups and controls.

0.74-1.35) [11]. Four studies including 1785 patients have assessed this endpoint. A single randomized clinical trial comparing liberal and restrictive use of oxygen in ICU patients showed an increased rate of HAP in the liberal group [13]. Three randomized clinical trials assessing hyperoxia exposure for $24 \mathrm{~h}$ or less found no differences in HAP incidence [26-28]. Of note, the effect of hyperoxia exposure on the development of HAP seems time-dependent. Indeed, shorter was hyperoxia duration better was the outcome. [13,26-28] Moreover, experimental results showed an impairment of immunologic function if hyperoxia exposure was prolonged. [29] In murine models, exposure to hyperoxia between 24 and $60 \mathrm{~h}$ was associated with lung impairment and more induced infection related to legionella, and Pseudomonas aeruginosa. [30-32] In contrast, no immune alterations were found for shortduration hyperoxia exposure [33]. At the early stage of aggression, hyperoxia exposure can reduce infection by the antimicrobial effect of oxygen [22-24,33]. This may explain the association between early hyperoxia exposure and lower incidence of HAP in our study.

Our results may also suggest an association between early hyperoxemia and a lower occurrence of death and shorter mechanical ventilation exposure and shorter time of ICU stay. Despite the adjusted severity of blunt chest trauma, the patients with early hyperoxemia exposure trended to develop less morbidity, which suggests that the difference was probably not due to the primary injury. We hypothesized that the reduction of the inflammatory process could be reduced in the early hyperoxia group [34]. Short-duration hyperoxia exposure through mechanical ventilation in a blunt chest trauma mice model was associated with an abolishment of fracture healing impairment and a decrease in pro-inflammatory factors [35,36]. Regarding pulmonary complications, this model seems in line with our suggested results.

Our findings differ from those of some previous studies comparing liberal versus conservative oxygen exposure in critically ill patients.
Indeed, several studies reported deleterious effects of prolonged hyperoxemia. In a randomized clinical trial, Girardis et al. found increased ICU mortality in patients treated with a liberal oxygen therapy compared with those treated with a conservative strategy [13]. Those findings was confirmed in a meta-analysis reporting a deleterious effect of prolonged hyperoxia exposure over time in a heterogeneous patient population [11]. This effect might be due to the constitution of reactive oxygen species, which induce protein damage through their oxidative action $[37,38]$. In contrast, a multicenter randomized controlled trial, the ICU-ROX investigators found no difference in outcome in a heterogenous ICU patients receiving either liberal or conservative oxygen administration during the first $24 \mathrm{~h}$ of admission [12]. In post hoc analyses ICU-ROX investigators found that the only subgroup with worsening outcome associated with hyperoxemia was patients with suspected hypoxic-ischemic encephalopathy [12]. Another recent post hoc analysis of the ICU-ROX trial cannot rule out a potential harm of a conservative strategy compared with a liberal delivery of oxygen in patients with sepsis [39]. Those results suggest that the effect of hyperoxemia remains unclear and may be different regarding the population of patients and length of administration. Our study focused on severe blunt chest trauma patients with early hyperoxemia represents a specific population suffering of lack of data.

Our study has several limitations. First, it was an observational, retrospective study, only suggesting future directions for clinical research. To reduce the bias due to the study design, we performed a propensity score-based analysis. The early phase of management was considered, and it is unclear how late management affected the patients' outcomes. However, in our ICU, the patients are managed according to similar international guidelines, which probably reduced variability in oxygen levels like suggested in Fig. 2 because $\mathrm{PaO}_{2}$ values difference of blood gases trended to reduce at the end of the first $24 \mathrm{~h}$ of admission 


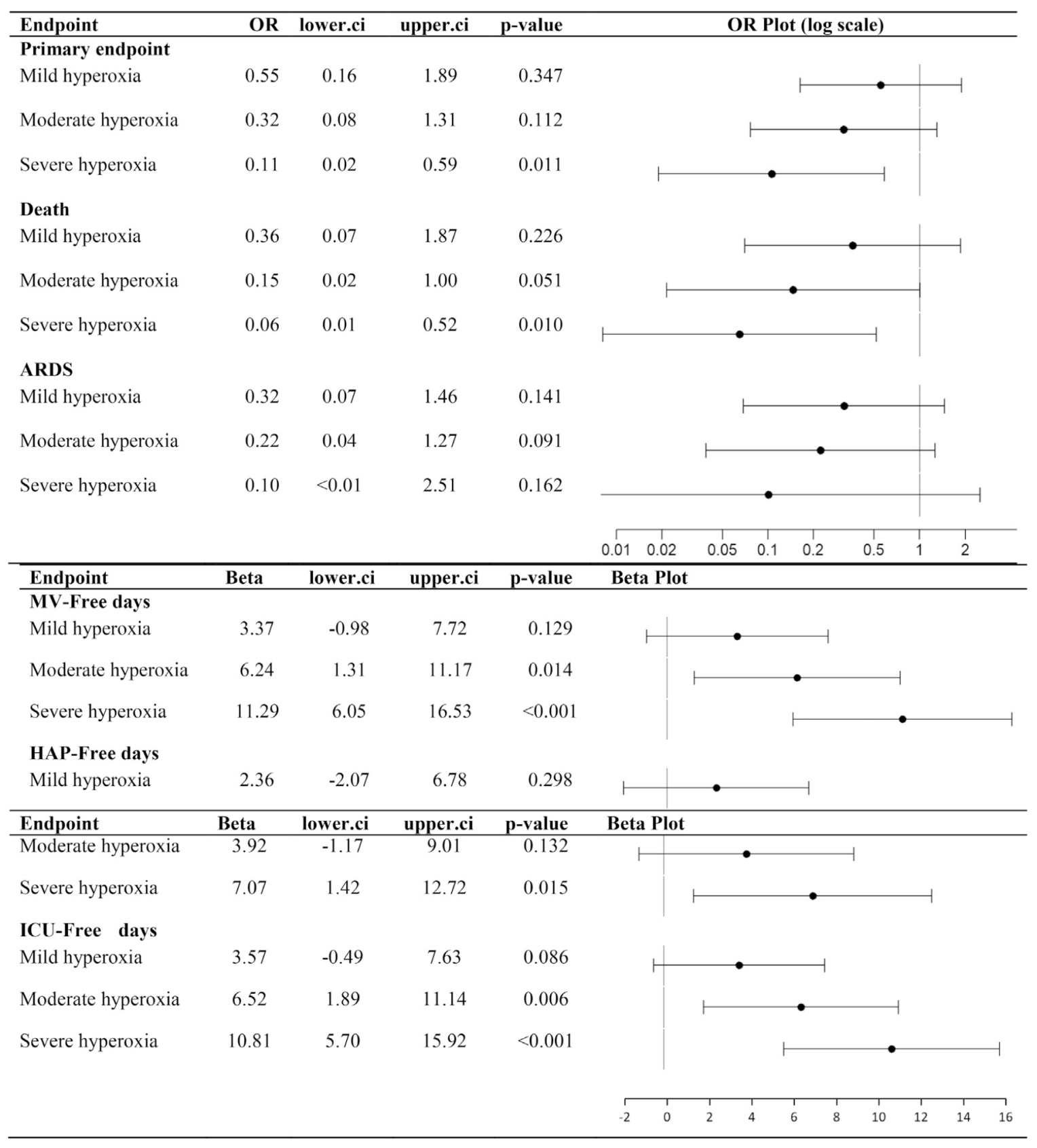

Fig. 3. Forest plot presenting results of propensity score analysis. ARDS: Acute respiratory distress syndrom, HAP: Hospital acquired pneumonia; ICU: Intensive care Unit; MV: Mechanical ventilation; OR: odd ratio.

(Fig. 2) $[6,20,40]$. Hemoglobin concentration are missing in our adjustment and some may consider that low $\mathrm{PaO}_{2}$ could be associated with missing oxygen carrying capacity rather than a pulmonary problem.
Considering severe hyperoxemia group received more blood transfusion associated with more severe injuries than the control group we may rule out this bias. The association between higher $\mathrm{PaO}_{2}$ and the

Table 2

Multivariate and marginal structural model analysis regarding $\mathrm{PaO}_{2}$ exposure and outcomes.

\begin{tabular}{|c|c|c|c|c|}
\hline & \multicolumn{2}{|c|}{ Multivariate regression } & \multicolumn{2}{|c|}{ Marginal structural model } \\
\hline & Odd Ratio [IC95\%] & $P$ & Odd Ratio [IC95\%] & $P$ \\
\hline Primary endpoint & $1.00[0.99-1.00]$ & 0.2 & $1.00[1.00-1.00]$ & 0.4 \\
\hline Death & $0.99[0.98-1.00]$ & 0.4 & $1.00[1.00-1.00]$ & 0.2 \\
\hline Days without HAP & $0.01[0.00-0.03]$ & 0.1 & $0.01[0.01-0.02]$ & 0.003 \\
\hline Days without mechanical ventilation & $0.03[0.01-0.05]$ & 0.001 & $0.01[0.00-0.01]$ & 0.01 \\
\hline $\begin{array}{l}\text { Days without } \\
\text { intensive care }\end{array}$ & $0.03[0.01-0.05]$ & 0.003 & $0.01[0.00-0.02]$ & 0.03 \\
\hline
\end{tabular}


$\mathrm{PaO}_{2}: \mathrm{FiO}_{2}$ ratio at ICU admission could be interpreted as a marker of lower severity in the hyperoxemia group but it has been shown that the $\mathrm{PaO}_{2}: \mathrm{FiO}_{2}$ ratio increased significantly if the $\mathrm{FiO}_{2}$ was above 0.7 [41]. However, our analyses were adjusted on the $\mathrm{FiO}_{2}$ level and we excluded patients with the more severe $\mathrm{PaO}_{2}: \mathrm{FiO}_{2}$ ratio alteration reducing this effect. This adjustment aimed to reduce the discrepancy between the hyperoxemic patients and the controls. Furthermore $\mathrm{PaO}_{2}: \mathrm{FiO}_{2}$ ratio $<200 \mathrm{mmHg}$ patients at admission were excluded because considered with severe respiratory or cardiovascular impairment preventing any possible hyperoxia. This would have artificially increased the difference between the control group and the hyperoxic groups by including the more severe patients in the normoxic group. Finally, the choice of average $24 \mathrm{~h} \mathrm{PaO}_{2}$ rather than the maximal $\mathrm{PaO}_{2}$ level remains a matter for discussion. In our opinion, averaging the measurements of blood gases, rather than a single measure, reflected with more accuracy the potential effect of hyperoxemia during the first hours of management. We excluded patient with length of ICU stay $<24$ h because we assume that death was not related to hyperoxemia but to severity of initial injuries.

In our cohort early hyperoxemia during the first $24 \mathrm{~h}$ of admission after severe blunt chest trauma was not associated with worse outcome regarding HAP and death occurrence. Further prospective and interventional investigations are necessary to confirm these findings in this specific population.

\section{Funding information}

This work did not receive any funding.

\section{Prior abstract presentation}

Preliminary results of this works were presented under the form of abstract during the national congress of Societe Française d'Anesthésie-Réanimation (SFAR) (Paris - September 2019).

\section{Author statement}

All authors assume the responsibility of data presented in this manuscript.

\section{Declaration of Competing Interest}

ML declare a competing interest with Amomed, Aguettant, MSD, $3 \mathrm{M}$, Pfizer, Aspen, Orion.

Other authors did not disclose conflict of interest.

\section{References}

[1] GBD 2017 Mortality Collaborators. Global, regional, and national age-sex-specific mortality and life expectancy, 1950-2017: a systematic analysis for the Global Burden of Disease Study 2017. Lancet Lond Engl 2018;392:1684-735. https://doi.org/ 10.1016/S0140-6736(18)31891-9.

[2] Bège T, Pauly V, Orleans V, Boyer L, Leone M. Epidemiology of trauma in France: mortality and risk factors based on a national medico-administrative database. Anaesth Crit Care Pain Med 2019. https://doi.org/10.1016/j.accpm.2019.02.007.

[3] Chesnut RM. Secondary brain insults after head injury: clinical perspectives. New Horiz Baltim Md 1995;3:366-75.

[4] Leone M, Albanèse J, Rousseau S, Antonini F, Dubuc M, Alliez B, et al. Pulmonary contusion in severe head trauma patients: impact on gas exchange and outcome. Chest 2003;124:2261-6. https://doi.org/10.1378/chest.124.6.2261.

[5] Leone M, Brégeon F, Antonini F, Chaumoître K, Charvet A, Ban LH, et al. Long-term outcome in chest trauma. Anesthesiology 2008;109:864-71. https://doi.org/10. 1097/ALN.0b013e31818a4009.

[6] Bouzat P, Raux M, David JS, Tazarourte K, Galinski M, Desmettre T, et al. Chest trauma: first 48hours management. Anaesth Crit Care Pain Med 2017;36:135-45. https://doi.org/10.1016/j.accpm.2017.01.003.

[7] ACo S. ATLS Student Course Manual : Advanced Trauma Life Support. 9th ed.; 2012.
[8] Eskesen TG, Baekgaard JS, Steinmetz J, Rasmussen LS. Initial use of supplementary oxygen for trauma patients: a systematic review. BMJ Open 2018;8:e020880. https://doi.org/10.1136/bmjopen-2017-020880.

[9] Eskesen TG, Baekgaard JS, Christensen RE, Lee JM, Velmahos GC, Steinmetz J, et al. Supplemental oxygen and hyperoxemia in trauma patients: A prospective, observational study. Acta Anaesthesiol Scand 2019;63:531-6. https://doi.org/10.1111/aas. 13301.

[10] McMullan J, Rodriquez D, Hart KW, Lindsell CJ, Vonderschmidt K, Wayne B, et al. Prevalence of prehospital hypoxemia and oxygen use in trauma patients. Mil Med 2013;178:1121-5. https://doi.org/10.7205/MILMED-D-13-00126.

[11] Chu DK, Kim LH-Y, Young PJ, Zamiri N, Almenawer SA, Jaeschke R, et al. Mortality and morbidity in acutely ill adults treated with liberal versus conservative oxygen therapy (IOTA): a systematic review and meta-analysis. Lancet Lond Engl 2018; 391:1693-705. https://doi.org/10.1016/S0140-6736(18)30479-3.

[12] ICU-ROX Investigators and the Australian and New Zealand Intensive Care Society Clinical Trials Group, Mackle D, Bellomo R, Bailey M, Beasley R, Deane A, et al. Conservative oxygen therapy during mechanical ventilation in the ICU. N Engl J Med 2019. https://doi.org/10.1056/NEJMoa1903297.

[13] Girardis M, Busani S, Damiani E, Donati A, Rinaldi L, Marudi A, et al. Effect of conservative vs conventional oxygen therapy on mortality among patients in an intensive care unit: the oxygen-ICU randomized clinical trial. JAMA 2016;316:1583-9. https:// doi.org/10.1001/jama.2016.11993.

[14] Ó Briain D, Nickson C, Pilcher DV, Udy AA. Early Hyperoxia in patients with traumatic brain injury admitted to intensive Care in Australia and new Zealand: A retrospective multicenter cohort study. Neurocrit. Care. 2018;29:443-51. doi:https://doi. org/10.1007/s12028-018-0553-5.

[15] von Elm E, Altman DG, Egger M, Pocock SJ, Gøtzsche PC, Vandenbroucke JP, et al. The strengthening the reporting of observational studies in epidemiology (STROBE) statement: guidelines for reporting observational studies. J Clin Epidemiol 2008: 61:344-9. https://doi.org/10.1016/j.jclinepi.2007.11.008.

[16] Osler T, Baker SP, Long W. A modification of the injury severity score that both improves accuracy and simplifies scoring. J Trauma 1997;43:922-5 [discussion 925926].

[17] Toulouse E, Masseguin C, Lafont B, McGurk G, Harbonn A, A Roberts J, et al.. French legal approach to clinical research. Anaesth Crit Care Pain Med 2018;37:607-14. https://doi.org/10.1016/j.accpm.2018.10.013.

[18] Frat J-P, Thille AW, Mercat A, Girault C, Ragot S, Perbet S, et al. High-flow oxygen through nasal cannula in acute hypoxemic respiratory failure. N Engl J Med 2015; 372:2185-96. https://doi.org/10.1056/NEJMoa1503326.

[19] Definition Task Force ARDS, Ranieri VM, Rubenfeld GD, Thompson BT, Ferguson ND, Caldwell E, et al. Acute respiratory distress syndrome: the Berlin Definition. JAMA 2012;307:2526-33. https://doi.org/10.1001/jama.2012.5669.

[20] Leone M, Bouadma L, Bouhemad B, Brissaud O, Dauger S, Gibot S, et al. Brief summary of French guidelines for the prevention, diagnosis and treatment of hospitalacquired pneumonia in ICU. Ann Intensive Care 2018;8:104. https://doi.org/10 1186/s13613-018-0444-0.

[21] Leone M, Bouadma L, Bouhemad B, Brissaud O, Dauger S, Gibot S, et al. Hospitalacquired pneumonia in ICU. Anaesth Crit Care Pain Med 2018;37:83-98. https:// doi.org/10.1016/j.accpm.2017.11.006.

[22] Kiers D, Gerretsen J, Janssen E, John A, Groeneveld R, van der Hoeven JG, et al. Shortterm hyperoxia does not exert immunologic effects during experimental murine and human endotoxemia. Sci Rep 2015;5:17441. https://doi.org/10.1038/ srep 17441.

[23] O'Reilly PJ, Hickman-Davis JM, Davis IC, Matalon S. Hyperoxia impairs antibacterial function of macrophages through effects on actin. Am J Respir Cell Mol Biol 2003: 28:443-50. https://doi.org/10.1165/rcmb.2002-01530C.

[24] Qadan M, Battista C, Gardner SA, Anderson G, Akca O, Polk HC. Oxygen and surgical site infection: a study of underlying immunologic mechanisms. Anesthesiology 2010;113:369-77. https://doi.org/10.1097/ALN.0b013e3181e19d1d.

[25] Allegranzi B, Zayed B, Bischoff P, Kubilay NZ, de Jonge S, de Vries F, et al. New WHO recommendations on intraoperative and postoperative measures for surgical site infection prevention: an evidence-based global perspective. Lancet Infect Dis 2016;16: e288-303. https://doi.org/10.1016/S1473-3099(16)30402-9.

[26] Asfar P, Schortgen F, Boisramé-Helms J, Charpentier J, Guérot E, Megarbane B, et al. Hyperoxia and hypertonic saline in patients with septic shock (HYPERS2S): a twoby-two factorial, multicentre, randomised, clinical trial. Lancet Respir Med 2017;5 180-90. https://doi.org/10.1016/S2213-2600(17)30046-2.

[27] Stub D, Smith K, Bernard S, Bray JE, Stephenson M, Cameron P, et al. A randomized controlled trial of oxygen therapy in acute myocardial infarction Air Verses Oxygen In myocarDial infarction study (AVOID Study). Am Heart J 2012;163:339-45 e1 https://doi.org/10.1016/j.ahj.2011.11.011.

[28] Schietroma M, Cecilia EM, De Santis G, Carlei F, Pessia B, Amicucci G. Supplemental Peri-operative oxygen and incision site infection after surgery for perforated peptic ulcer: A randomized, double-blind monocentric trial. Surg Infect 2016;17:106-13. https://doi.org/10.1089/sur.2013.132.

[29] Damiani E, Donati A, Girardis M. Oxygen in the critically ill: friend or foe? Curr Opin Anaesthesiol 2018;31:129-35. https://doi.org/10.1097/ACO.0000000000000559.

[30] Tateda K, Deng JC, Moore TA, Newstead MW, Paine R, Kobayashi N, et al. Hyperoxia mediates acute lung injury and increased lethality in murine Legionella pneumonia: the role of apoptosis. J Immunol Baltim Md 1950;2003(170):4209-16. https://doi. org/10.4049/jimmunol.170.8.4209.

[31] Kikuchi Y, Tateda K, Fuse ET, Matsumoto T, Gotoh N, Fukushima J, et al. Hyperoxia exaggerates bacterial dissemination and lethality in Pseudomonas aeruginosa pneumonia. Pulm Pharmacol Ther 2009;22:333-9. https://doi.org/10.1016/j.pupt.2008. 12.021 . 
[32] Nagato AC, Bezerra FS, Lanzetti M, Lopes AA, Silva MAS, Porto LC, et al. Time course of inflammation, oxidative stress and tissue damage induced by hyperoxia in mouse lungs. Int J Exp Pathol 2012;93:269-78. https://doi.org/10.1111/j.1365-2613.2012. 00823.x.

[33] Calzia E, Asfar P, Hauser B, Matejovic M, Ballestra C, Radermacher P, et al. Hyperoxi may be beneficial. Crit Care Med 2010;38:S559-68. https://doi.org/10.1097/CCM. 0b013e3181f1fe70.

[34] Ramin S, Charbit J, Jaber S, Capdevila X. Acute respiratory distress syndrome after chest trauma: epidemiology, specific physiopathology and ventilation strategies. Anaesth Crit Care Pain Med 2019;38:265-76. https://doi.org/10.1016/j.accpm. 2018.09.009.

[35] Kemmler J, Bindl R, McCook O, Wagner F, Gröger M, Wagner K, et al. Exposure to $100 \%$ oxygen abolishes the impairment of fracture healing after thoracic trauma. PLoS One 2015;10:e0131194. https://doi.org/10.1371/journal.pone.0131194.

[36] Wagner K, Gröger M, McCook O, Scheuerle A, Asfar P, Stahl B, et al. Blunt chest trauma in mice after cigarette smoke-exposure: effects of mechanical ventilation with 100\% O2. PLoS One 2015;10:e0132810. https://doi.org/10.1371/journal.pone. 0132810 .
[37] Jamieson D, Chance B, Cadenas E, Boveris A. The relation of free radical production to hyperoxia. Annu Rev Physiol 1986;48:703-19. https://doi.org/10.1146/annurev.ph. 48.030186.003415.

[38] Hafner S, Beloncle F, Koch A, Radermacher P, Asfar P. Hyperoxia in intensive care, emergency, and peri-operative medicine: Dr. Jekyll or Mr. Hyde? A 2015 update. Ann. Intensive Care 2015;5:42. doi:https://doi.org/10.1186/s13613-015-0084-6.

[39] Young P, Mackle D, Bellomo R, Bailey M, Beasley R, Deane A, et al. Conservative oxygen therapy for mechanically ventilated adults with sepsis: a post hoc analysis of data from the intensive care unit randomized trial comparing two approaches to oxygen therapy (ICU-ROX). Intensive Care Med 2020;46:17-26. https://doi.org/10. 1007/s00134-019-05857-X.

[40] Leone M, Constantin J-M, Dahyot-Fizelier C, Duracher-Gout C, Joannes-Boyau O, Langeron $\mathrm{O}$, et al. French intensive care unit organisation. Anaesth Crit Care Pain Med 2018;37:625-7. https://doi.org/10.1016/j.accpm.2018.10.011.

[41] Allardet-Servent J, Forel J-M, Roch A, Guervilly C, Chiche L, Castanier M, et al. FIO2 and acute respiratory distress syndrome definition during lung protective ventilation. Crit Care Med 2009;37:202-7 e4-6 https://doi.org/10.1097/CCM. 0b013e31819261db. 